\title{
The Socio-economic Characteristics of Wheat Farmers Regarding Adoption of Sustainable Soil Management (SSM)
}

\author{
Azadeh N. Noorivandi ${ }^{1}$, Abdolazim Ajili ${ }^{2}$, Mohammad Chizari ${ }^{3}$ and Masoud Bijani ${ }^{4}$ \\ ${ }^{1}$ Islamic Azad University, Shoushtar Branch, Iran \\ ${ }^{2,4}$ Agricultural and Natural Resources University Ramin, Ahwaz, Iran \\ ${ }^{3}$ College of Agriculture, Tarbiat Modares University, Tehran, Iran
}

KEYWORDS Sustainability. Sustainable Soil Management (SSM). Farmers

\begin{abstract}
Sustainable Soil Management (SSM) practices have tended to reduce the use of fertilizer pesticides, and maximal tillage, but rely more on crop rotation, crop residues, animal manure, green manure, leguminous, appropriate mechanical control or minimal tillage to optimize soil conservation activity. The purpose of this article was to identify socio-economic characteristics of farmers regarding adoption of sustainable soil management by wheat farmers in Modares Watershed Region of Khuzestan Province,_Iran. The employed research method was correlativedescriptive. Wheat farmers in this region were the target population for this study. A random sample of wheat farmers selected $(\mathrm{N}=1185, \mathrm{n}=293)$. An indicator for analysis of Sustainable Soil Management (SSM) has been developed for determining level of soil sustainability of wheat farmers. According to survey results, $15.8 \%$ of respondents reported their sustainability to be "unsustainable", approximately $59.2 \%$ of respondents reported their sustainability to be "moderate", and remains were sustainable. According to survey results, correlation between socio-economic characteristics such as income, land size, level of mechanization, social participation, social status, crop yield, rate of loan and sustainable soil management (SSM) Index was significant. Also there was significant relationship between personal characteristics such as level of education, technical knowledge, perception of farmers and sustainable soil management (SSM) Index. Liner regression used for predict changes in level of SSM Index. Income, level of education, social participation, social status, crop yield, level of mechanization and technical knowledge of farmers may well explain for $81 \%$ changes $\left(\mathrm{R}^{2}=0.81\right)$ in level of SSM Index.
\end{abstract}

\section{INTRODUCTION}

Soil erosion is one of the major factors that cause low crop yields in Southwest of Iran, because conservation and sustainable agriculture practices require farmers to spend more time planning, thinking, and developing a strategy for managing farming systems to attain a sustainable agriculture. Nowak (1987) noted that inefficiencies in the development and delivery of relevant information and assistance contributed to poor adoption rates of conservation technologies. Useful information, appropriate technology, and sound advices needed to overcome these inefficiencies. This research may present useful information on soil conservation technology for decision makers in Iran who are attempting to increase the adoption of soil conservation technologies.

Numerous studies have been conducted on agricultural technology adoption in the last 30 years, ranking the 'adoption issue' high on the economics research agenda (Dimara and Skuras 2003). Ommani and Chizari (2006) stated that lack of financial incentives inhibited adoption of new technology.

Chizari et al. (2002) noted in their research, majority of Iranian farmers tended to agree or were unsure about soil conservation technology. Approximately $86 \%$ of farmers agreed that the government should pay farmers for the cost of practicing soil conservation technology and $80 \%$ of farmers agreed that soil conservation and controlling erosion were both important and essential.

Sustainable agriculture practices have tended to reduce the use of fertilizer pesticides, and maximal tillage, but rely more on crop rotation, crop residues, animal manure, green manure, leguminous, appropriate mechanical cultivation or minimal tillage to optimize soil and natural pest control activity (Ommani and Chizari 2006). Many groups of researchers are trying to define sustainability indicators and to devise methods to monitor them in field condition (Benites et al. 1998 and Ommani 2001).

According to Smyth and Dumanski (1994), Sustainable Land Management (SLM) is indicator for assessing sustainability. Sustainable land management (SLM) describes the complementary goals of maintaining and enhancing the quality of the land, while providing economic, social and environmental opportunities for the benefit of present and future generations. SLM can be 
assessed by evaluating enhancement of productivity, reduction of risk, enhancement of environmental quality, economic and social acceptability. According to Taylor et al. (1993), Farm Sustainability Index (FSI) is other indicator for assessing sustainability. Their research showed that farm sustainability index describes appropriate techniques for pest and weed control, soil conservation and soil productivity. Ommani (2001) indicated the need for indicators of sustainability linked to issues discussed in Agenda 21. The United Nation Conference on Environment and Development (UNCED) meeting in Rio resulted in series of new initiatives on assessment of sustainability by other international institutions. UNCED's Agenda 21 itself as agreed upon by participating governments, specifies desired actions on environmental protection and sustainable development (Sombroek 1994). Ommani (2008); points out, relationship among components that is describing aspects of sustainability. This relationship was explained in the following formula:

$$
S=f\left[\sum_{i=1}^{8} X i, \sum_{j=1}^{3} Y j\right]
$$

Consequently, sustainability is the successful management of resources to satisfy the challenging human needs, while maintaining or enhancing the quality of environment and conserving natural resources. A schedule was developed and data were collected of farmers in Khuzestan Province of Iran for the analysis of sustainable soil management. The sustainable soil management was divided into multiple broad components, which includes components that were described in formula.

$$
S=f\left[\sum_{i=1}^{8} X i-\sum_{j=1}^{3} Y j\right]
$$

$\mathrm{X}_{1}=$ Average of crop yield

$\mathrm{X}_{2}=$ Using legume in farming rotation

$\mathrm{X}_{3}=$ Using green manure

$\mathrm{X}_{4}=$ Using animal manure

$\mathrm{X}_{5}=$ Using water conservation

$\mathrm{X}_{6}=$ Using conservation tillage

$\mathrm{X}_{7}=$ Using Integrated Pest Management

$\mathrm{X}_{8}=$ farming control for pest and weed

$\mathrm{Y}_{1}=$ Rate of using chemical pesticide

$\mathrm{Y}_{2}=$ Rate of using chemical weed killer

$\mathrm{Y}_{3}^{2}=$ Rate of using chemical manure
Sustainability indicators should provide information on the environmental components of the farming system. For the study, an indicator for analysis of Sustainable Soil Management (SSM) has been developed. The objectives of research were:

1- Describing wheat farmers in Modares Watershed Region of Khuzestan Province by demographic characteristics.

2- Analyzing of sustainable soil management in Modares Watershed Region.

3- Identifying perception of wheat farmers regarding economic and social traits of sustainable soil management.

4 Identifying correlation between socioeconomic characteristics with level of sustainable soil management (SSM) Index.

\section{METHODOLOGY}

The data were collected between January and April 2008 through a questionnaire. The employed research method was correlative-descriptive. The population consisted of wheat farmers of Modares Watershed Region of Khuzestan Province, Iran. A random sample of wheat farmers $(\mathrm{N}=1185$, $\mathrm{n}=293$ ) was selected. The questionnaire was developed to collect data (Bantilan et al. 2004; Sombroek 1994 and Ommani 2001). The sections of questionnaire were: a) demographic characteristics, b) sustainable soil management items and c) perception of wheat farmers regarding economic and social traits of sustainable soil management. Content and face validity were established by a panel of experts of faculty members at Tarbiat Modares University of Tehran. A pilot test was conducted with 30 wheat farmers in Dezful Township. Questionnaire reliability was estimated by calculating Cronbach,'s alpha. Reliability for the overall instrument was estimated at 0.87. Data collected were analyzed using the Statistical Package for the Social Sciences (SPSS). Appropriate statistical procedures for description (frequencies, percent, means, and standard deviation) were used.

\section{FINDINGS}

\section{Objective 1}

The first objective was to describe wheat farmers in Modares Watershed Region of Khuzestan Province by demographic charac- 
teristics. Majority of respondents were male (90\%). Approximately $27.4 \%$ of respondents were between 31 to 40 years of age (Table 1). Farmers were asked to report their highest level of education: approximately: $37 \%$ of farmers had an elementary education and $7.99 \%$ had high school diploma and post high school education.

Table 1: The age of 292 wheat farmers in Modarres Watershed Region Kouzestan province, Iran, conducted in 2008.

\begin{tabular}{lrrr}
\hline Age & $f$ & $\%$ & Cum \% \\
\hline $20-30$ & 23 & 7.9 & 7.9 \\
$31-40$ & 80 & 27.4 & 35.3 \\
$41-50$ & 114 & 39 & 74.3 \\
$51-60$ & 53 & 18.2 & 92.5 \\
61 and above & 22 & 7.5 & 100 \\
& 292 & 100 & \\
\hline
\end{tabular}

Table 2: The socio-economic characteristics of 292 wheat farmers in Modarres Watershed Region Kouzestan province, Iran, conducted in 2008.

\begin{tabular}{lcr}
\hline $\begin{array}{l}\text { Socio-economic } \\
\text { characteristics }\end{array}$ & Mean & $S d$ \\
\hline Income & $51.2($ Million Rial) & 4.9 \\
Crop yield & $3.3($ Ton) & 0.7 \\
Social participation & $3 *$ & 1 \\
Land size & $5.3($ hec) & 4.6 \\
Level of Mechanization & $3 *$ & 1.5 \\
Loan & 15 (Million Rial) & 8.9 \\
\hline * &
\end{tabular}

* Scale: $1=$ Very low, $2=$ Low, $3=$ Moderate, $4=$ High, $5=$ Very high

\section{Objective 2}

The second objective was analysis of SSM in Modares Watershed Region. For the study an Indicator for Analysis of SSM has been developed based of literature review in this context for determining level of sustainable soil management of wheat farmers in Modares Watershed Region of Khuzestan province of Iran. The sustainable soil management was divided into multiple broad components, which includes components that were described in formula.

$$
S=f\left[\sum_{i=1}^{8} X i-\sum_{j=1}^{3} Y j\right]
$$

$\mathrm{X}_{1}=$ Using zero tillage

$\mathrm{X}_{2}=$ Using legume in farming rotation

$\mathrm{X}_{3}=$ Using green manure

$\mathrm{X}_{4}=$ Using animal manure

$\mathrm{X}_{5}=$ Using water conservation

$\mathrm{X}_{6}=$ Using conservation tillage
$\mathrm{X}_{7}=$ Using Integrated Pest Management

$\mathrm{X}_{8}=$ farming control for pest and weed

$\mathrm{Y}_{1}=$ Rate of using chemical pesticide

$Y_{2}=$ Rate of using chemical weed killer

$\mathrm{Y}_{3}=$ Rate of using chemical manure

Table 3 provides ranking of different level of SSM based on using multiple broad components of soil sustainability by wheat farmers. This table shows that $15.8 \%$ of farmers had unsustainable soil management and approximately $25 \%$ of them were sustainable.

Table 3: Level of SSM Index of 292 wheat farmers in Modarres Watershed Region Kouzestan province, Iran, conducted in 2008.

\begin{tabular}{lrr}
\hline Level of Sustainability & $f$ & $\%$ \\
\hline Unsustainable & 46 & 15.8 \\
Moderate sustainable & 173 & 59.2 \\
Sustainable & 73 & 25.0 \\
\hline & 292 & 100.0 \\
\hline
\end{tabular}

\section{Objective 3}

The third objective was to assess perceptions of wheat farmers regarding economic and social traits of SSM. For the measurement of perception of the respondents about economic and social aspects of sustainability, the farming system technology was divided into seven broad components, which includes using zero tillage, using legume in farming rotation, using green manure, using animal manure, using water conservation, using conservation tillage, using Integrated Pest Management, and farming control for pest and weed. Overall, farmers tended to unsure about economic and social traits of sustainable soil management. Table 4 shows that $26.96 \%$ of farmers were strongly agree regarding economic and social traits of sustainability of farming system.

Table 4: Perception of farmers regarding economic and social traits of sustainable soil management

\begin{tabular}{lrrr}
\hline Level of perception & $f$ & $\%$ & Cum \% \\
\hline Strongly agree & 79 & 26.96 & 26.96 \\
Agree & 61 & 20.82 & 47.78 \\
Unsure & 57 & 19.45 & 67.23 \\
Disagree & 60 & 20.48 & 87.71 \\
Strongly disagree & 36 & 12.20 & 100.00 \\
\hline \multicolumn{2}{r}{} \\
\hline
\end{tabular}

\section{Objective 4}

The forth objective was to identify correlation between socio-economic characteristics with 
level of SSM Index. There was a significant relationship between socio-economic characteristics such as income, land size, level of mechanization, social participation, social status, crop yield and rate of loan with SSM Index. In addition, there was significant relationship between personal characteristics such as level of education, technical knowledge and perception of farmers with SSM Index.

Liner regression used for predict changes in level of SSM Index. Income, level of education, social participation, social status, crop yield, level of mechanization and technical knowledge of farmers may well explain for $81 \%$ changes $\left(\mathrm{R}^{2}=0.81\right)$ in level of SSM Index. This relationship is described in the following formula:

$\mathrm{Y}=14.54+0.255 \mathrm{x}_{1}+0.542 \mathrm{x}_{2}+0.547 \mathrm{x}_{3}+0.541 \mathrm{x}_{4}$ $+0.254 \mathrm{x}_{5}+0.512 \mathrm{x}_{6}+0.314 \mathrm{x}_{7}$

\section{RECOMMENDATIONS AND EDUCATIONAL IMPORTANCE}

The essential condition for farming sustainability is that large numbers of farming households must be motivated to learn indicator of sustainability and use coordinated resource management. Indicators for soil sustainability are pointers, which would be used to reveal and monitor the conditions and trends in farming system sector. According to results, wheat farmers should be taught about the using water conservation, using conservation tillage, using Integrated Pest Management, and farming control for pests and weeds. Extension service training courses could be useful to teach wheat farmers in this regard. In recent years, an increasing number of studies have shown that participation by local people is one of vital components of success in sustainable agriculture (Ommani 2008). These approaches represent an opportunity to increase the learning from farmers. Farmers are largest group of users and managers of land, water, and other resources throughout the world. The majority of these men, women, and young farmers will need useful information, appropriate technology, and sound technical advice not only to increase their agricultural productivity and income, but also to make farming and rural life more sustainable.

Table 5: Correlation between selected independent variables with level of SSM Index

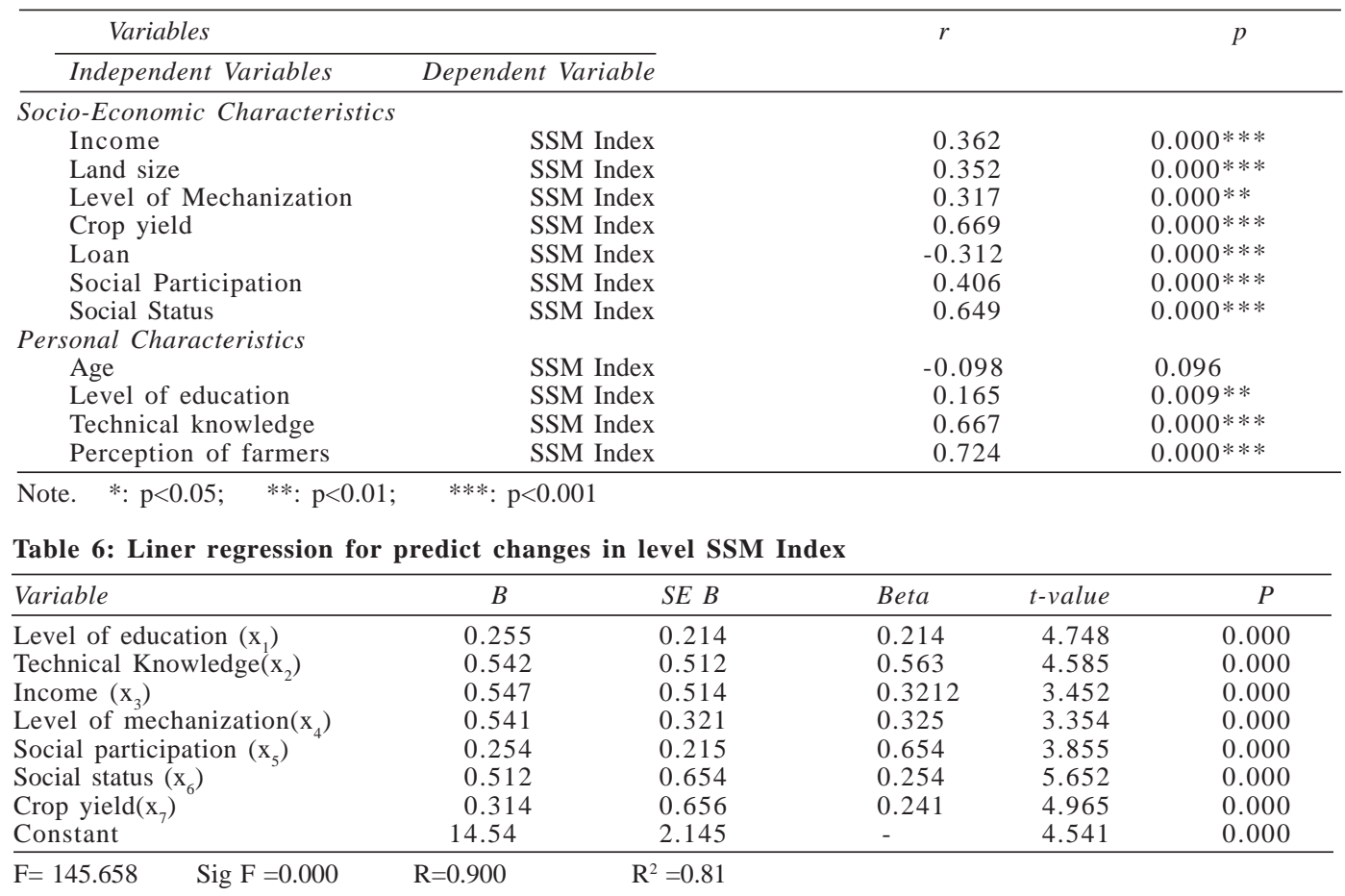




\section{REFERENCES}

Bantilan MCS, Rao KPC, Singh K, Parthasarathy P, Shiferaw B, Padmaja R 2004. Strategic Assessments and Development Pathways for Agriculture in the Semi-Arid Tropics. Policy Brief, No: 6. India: International Crops Research Institute for the SemiArid Tropics Patancheru, Andhra Pradesh.

Benites JR, Shaxson F, Vieira M 1998. Land condition change indicators for sustainable land resource management. In: FAO (Ed.): Land Quality Indicators and Their Use in Sustainable Agriculture and Rural Development, Rome: FAO, pp. 57-77.

Chizari M, Karimi S, Lindner J 2002. A Needs Assessment of Soil Conservation Competencies for Farmers in the Markazi Province of Iran. Proceedings of the 18th Annual WEEC Conference in Durban, South Africa.

Dimara E, Skuras D 2003. Adoption of agricultural innovations as a two-stage partial observability process. Agricultural Economics, 28: 187-196.

Lucila M, Lapar A and Pandey S 1999. Adoption of soil conservation: the case of the Philippine uplands. Agricultural Economics, 21: 241-256.

Nowak PJ 1987. The adoption of agricultural conservation technologies: economic and diffusion explanations. Rural Sociology, 52: 208-220.

Ommani AR, Chizari M. 2008. The analysis of farming system sustainability of wheat farmers in Khuzestan province of Iran. Green Farming. An International Journal of Agricultural Sciences, 1(6): 5-9.

Ommani AR 2008. Identifying Extension Mechanisms for Supporting Sustainable Water Resource Management in Agriculture. Ph.D thesis (Unpublished), Tehran: Islamic Azad University Science and Research Branch, Tehran.

Ommani, AR 2001. Determining Social, Economical and Farming Characteristics of Wheat Farmers in Khuzestan Province of Iran Regarding Adoption of Low Input Sustainable Agriculture (LISA). M.Sc Thesis (Unpublished), Thran: Tarbiat Modarres University.

Ommani AR, Chizari M 2006. An Analysis of Farming System Sustainability. Iranian Journal of Agricultural Science, 37(2): 120-136 (in Persian).

Smyth AJ, Dumanski J 1994. FESLM: An Environmental Framework for Evaluating Sustainable Land Management. World Soil Resources Report 73. Rome: FAO.

Sombroek WG 1998. Land resources evaluation and the role of land-related indicators. In: FAO (Ed.): Land Quality Indicators and Their Use in Sustainable Agriculture and Rural Development, Rome: FAO, pp. 9-19.

Taylor D, Mohamed Z, Shamsudin M 1993. Creating a farm sustainability index. American Journal of Alternative Agriculture, 8(4): 175-184. 